\title{
Exploring Students' Reading Profiles to Guide a Reading Intervention Programme
}

\author{
Naomi A. N. Y. Boakye ${ }^{1}$ \\ ${ }^{1}$ University of Pretoria, South Africa \\ Correspondence: Naomi A. N. Y. Boakye, University of Pretoria, South Africa. E-mail: \\ Naomi.Boakye@up.ac.za
}

Received: February 6, 2017

Accepted: June 8, 2017 Online Published: June 11, 2017

doi: $10.5539 /$ elt.v10n7p158

URL: http://doi.org/10.5539/elt.v10n7p158

\begin{abstract}
There have been a number of studies on reading interventions to improve students' reading proficiency, yet the majority of these interventions are undertaken with the assumption that students' reading challenges are obvious and generic in nature. The interventions do not take into consideration the diversity in students' reading backgrounds and the specific nature of the challenges. Thus interventions may not address students' specific reading needs. This paper reports on a study that explored students' reading profiles as a needs analysis for an intervention programme to improve the reading proficiency of first-year Sociology students. The aim was to investigate the students' reading backgrounds to determine their specific reading needs. A Likert scale questionnaire with an open-ended section was used to explore the students' reading profiles. The Likert scale questions were analysed quantitatively, while the open-ended questions were analysed qualitatively. In addition, a regression analysis was conducted to determine the correlation between students' use of strategies and their self-efficacy levels. The findings show that a number of students have little reading experience, use inappropriate reading strategies, and have low self-efficacy and poor reading habits. In addition, students identified comprehension, language, vocabulary, length and density of Sociology texts as factors compounding their reading challenges. This paper discusses the implications of these findings in designing an appropriate reading intervention programme for this cohort.
\end{abstract}

Keywords: reading profiles, needs analysis, reading intervention, reading challenges

\section{Introduction}

Reading is a fundamental skill that is essential for successful education. Students read to obtain information, and also to acquire knowledge in their various disciplines. These purposes for reading, require among others comprehension and the use of effective reading strategies to obtain meaning. Reading at tertiary level requires much more than basic comprehension or decoding; it requires students to synthesise information from various sources, read high volumes of texts within limited time frames, read to learn - which involves high levels of comprehension - and to read critically, making inferences and evaluating texts (Boakye, 2012; Grabe \& Stoller, 2011; Pretorius, 2000). A student must therefore be a proficient reader in order to engage with academic texts successfully. As fundamental as reading is, it is also a complex activity that requires complex processes (Alderson, 2000; Grabe \& Stoller, 2011). The complexity is compounded by subject-specific texts that require understanding of concepts and complex theories. In the reading of subject-specific texts, students have to make sense of theories, understand concepts and use information to present arguments. Sociology, as a discipline, requires large amounts of reading of texts that are often abstract in nature and contain various theories that are new to students. According to Roberts and Roberts (2008, p. 125), reading in Sociology 'is a complex process to which sociologists have paid little attention, despite the fact that [they] do a great deal of it and expect [their] students to do it before coming to classes'. Reading in Sociology, like many other subjects at university, requires 'deep reading' (Howard, 2004; Roberts \& Roberts, 2008; Yamane, 2006), what Yamane (2006, p. 238) refers to as 'engagement of higher-order thinking skills'. Deep reading requires the reader to be mentally engaged, motivated, and strategic (Sousa, 2006). According to Roberts and Roberts (2008) deep reading requires engagement with the material and connections to semantic or long term memory. However, a number of students do not have the required skills or the ability to use appropriate strategies to engage in this kind of reading. As stated by Roberts and Roberts (2008, p. 126) '[t]hese students are often in our classes hoping to be successful 
and needing help with comprehension techniques'. In order to assist such first-year Sociology students to engage in deep reading and be able to read effectively, an intervention that provides reading support to them is required. However, as in language-related courses, a needs analysis is an important point of departure if one wants to structure effective and appropriate reading interventions for students (Chen, 2006).

A needs analysis helps to determine the needs of a group of learners (Garcia, 2010; Veena, 2016). Veena (2016, p. 440) states that '[it] plays a crucial role and becomes a mandatory phase in the process of syllabus/curriculum design'. Richards (2002, p. 442) explains that a needs analysis should be undertaken for several reasons, including to highlight the needs of a particular category of learners in order to train them in a specific skill; to collect information about a particular problem the learners are experiencing; and to gather information about the learners on their attitudes, experiences and backgrounds. Thus, in order to ascertain the reading needs of first-year Sociology students, their reading backgrounds and specific reading challenges in Sociology were explored.

Reading researchers acknowledge the influence of students' backgrounds on their reading proficiency (e.g. Alderson, 2000; Grabe \& Stoller, 2011; Guthrie, 2008; Pretorius, 2000; Taylor \& Yu, 2009). They point out that factors such as students' reading experiences both at home and at school, their attitudes, self-efficacy, use of strategies, reading habits, and socioeconomic status, contribute to their reading proficiency. Yet, little empirical attention has been paid to the effects of these factors in the reading of Sociology texts and more so in providing a needs assessment for an intervention in the reading of such texts. The study was therefore undertaken to bridge this empirical gap and to determine the cohort of first-year students' specific reading needs in Sociology. Hence the paper reports on a needs analysis for a reading intervention in Sociology. The paper first discusses the relevance of a needs analysis. Thereafter, possible factors relating to students' reading backgrounds are discussed, together with challenges relating to the reading of Sociology texts. Finally, the study is presented and the results are discussed quantitatively with qualitative examples. Recommendations are made in terms of an appropriate reading intervention programme for this cohort of first-year Sociology students based on the needs analysis.

\subsection{Reading in Sociology}

According to Brenner (2015), many students find the reading of texts in the social sciences (the discipline to which Sociology belongs) unwieldy and dull, and therefore need to be taught appropriate reading strategies. He adds that these texts usually require high level inferencing, which makes them difficult to read. Sociology students have to read critically, as they have to make generalisations, evaluate arguments, distinguish between fact and opinion, detect bias, and interpret theories, among others (Ibid). He recommends teaching Sociology students strategies, such as accessing background knowledge and applying knowledge of text structure to facilitate comprehension (Ibid). It is important for students to to access prior knowledge when reading difficult texts as students have to make connections among a variety of topics and determine relevance in the text they are reading. In addition, Alderson (2000), Grabe and Stoller (2011), and Trabasso and Bouchard (2002) explain that knowledge of the text structure can be used to assist tertiary students in improving their reading comprehension. Students can be trained to utilise knowledge of the text structure to make mental summaries and predictions, and to understand relationships among ideas. Pelisson (2003) argues that the two main text structures prevalent in subjects such as Sociology (namely sequencing and giving the main idea with supporting details) pose challenges for first-year students. Comparing and contrasting structures are also highly relevant in Sociology, yet a number of students are unable to identify the structures that would facilitate comprehension of the texts. Another challenging task for students is reading and synthesising information from various sources in order to present valid arguments. This is particularly challenging for students who have had poor reading experiences and therefore may have low affective levels and consequently may not read. Roberts and Roberts (2008) point out that Sociology lecturers take the ability to read challenging texts for granted in their students, and expect them to read efficiently. Parrott and Cherry (2011) provide role-play activities that require students to support their claims with evidence. For example, they suggest that students take on roles such as reporter, connector and devil's advocate in discussion groups. A theoretical framework in reading engagement by Guthrie and Wigfield (2000) has been adapted by Boakye (2012) to include a needs analysis as a first step in any reading intervention programme. She states that in order to conduct an intervention that will yield optimal results, a needs analysis of students' affective and cognitive reading profiles should be conducted. Based on her adapted framework of cognitive and affective factors, and on the argument of other reading researchers (e.g. Grabe \& Stoller, 2011; Guthrie, 2008) that a needs analysis is crucial to effective intervention, the preliminary step of a reading intervention, which is a needs analysis that focuses on the students' reading backgrounds to determine their specific reading profiles, was undertaken. 


\subsection{Needs Analysis}

A needs analysis or assessment is described by Titcomb (2000) as a process of identifying and evaluating needs in a community or other defined population of people. She explains that the identification of needs should be seen as a process of describing the 'problems' of a target population and possible solutions to these problems.

Although Hutchinson and Waters (1987) point out that in language syllabuses, a needs analysis should consist of target needs and learning needs (i.e. objective needs), Garcia (2010) extends this idea by including affective needs (i.e. subjective needs), such as interests and attitudes. She argues that in a more modern view, needs should not be restricted to target and learning needs; affective needs should also be taken into consideration. She therefore combines affective and target needs in her study. The general background of the learners forms an important part of the affective needs. In a language-oriented course such as reading, students' backgrounds are important in determining their wants, wishes and gaps (Garcia, 2010). Thus, in academic reading where learners' affective reading levels and backgrounds are known to influence their reading proficiency, it is important to explore both the affective and learning needs. Information on learners' affective reading levels and backgrounds will determine the gap in their reading proficiency. According to Titcomb (2000) and Veena (2016), a need should be seen as a gap or lack. The aim of a syllabus or programme is therefore to meet learners' needs or fill this gap.

Confirming Hutchison and Waters' (1987) view, Garcia (2010) points out that a needs analysis should be conducted using different media, such as questionnaires, interviews, surveys, language tests, content analysis, statistical analysis and observation, and should be aimed at designing, improving or implementing language programmes. Veena (2016) adds that text analysis, interaction with students, and personal experiences should be used to identify students' needs and that it is essential to analyse needs from different perspectives. Thus, the first step in designing a language intervention programme is doing a needs analysis. It can be subjective or objective, and should be done from a learner perspective. It should include wants, necessities, wishes, expectations, lacks or gaps, as well as affective aspects, such as backgrounds, experiences, interests, and attitudes. A needs analysis is best conducted from various perspectives.

Although the importance of assessments to determine students' reading proficiency levels with a view to intervention cannot be denied, cognitive assessments alone do not provide a complete perspective. An exploration of students' backgrounds in reading will reveal specific needs that can be addressed in the intervention programme. In addition, various studies have shown a relationship between reading proficiency and the social, affective and cognitive aspects of reading (Dörnyei, 2001; Guthrie, 2008). The study therefore sought to investigate students' reading profiles from various perspectives.

\subsection{Background Factors That Influence Students' Reading Proficiency}

Although a number of factors related to students' backgrounds influence their reading proficiency (Grabe \& Stoller, 2011; Guthrie, 2008), the factors that were investigated in this study are (a) reading experience, (b) attitudes, (c) self-efficacy, (d) reading habits, (e) strategy use and (f) socioeconomic status. A number of studies have found a relationship between each of these factors and reading proficiency (Boakye 2012; Ghonsooly \& Elahi, 2010; Singhal, 2001; Van Staden \& Bosker, 2011). However, empirical studies investigating the reading of Sociology texts in relation to these factors are few. Roberts and Roberts (2008) assert that in Sociology 'there is almost nothing published in the way of empirical or theoretical analysis of reading in Sociology courses'. Since reading has been described as a complex skill involving various factors, it was necessary to explore students' reading in relation to these social, affective and cognitive factors in order to gain more insight into students' specific reading needs with regard to Sociology texts.

Various studies have shown that high affective levels in reading correspond with good, proficient reading whereas low affective levels indicate poor reading proficiency (e.g. Boakye, 2012; Guthrie, 2008). Other studies have shown that students who had poor reading instruction at school and poor reading experience, tend not to enjoy reading and consequently do not read to develop their reading ability (e.g. Boakye \& Southey, 2008; Pretorius, 2000). Six factors were considered in the needs analysis required for a reading intervention for this cohort of students, namely reading experience, attitudes towards reading, self-efficacy, use of strategies, reading habits and socioeconomic status.

\subsubsection{Reading Experience}

The reading experiences of students can have an enormous influence on their reading proficiency. Bandura (1986) and Vygotsky (1978) explain that a person's behaviour depends on his/her previous experiences and the surrounding social and cultural contexts. For example, a student who has had an impoverished reading 
experience at home and at school will probably not have a positive attitude towards reading at tertiary level and will therefore avoid reading or find it burdensome (Guthrie \& Wigfield, 2000). Students' past experiences with reading provide them with reading skills that form the foundation for developing important higher order academic reading skills (Van Staden \& Bosker, 2011).

\subsubsection{Reading Strategies}

According to Afflerbach, Pearson and Scott (2008), reading strategies are deliberate, goal directed attempts to control and modify the reader's effort to decode, understand and construct meaning from texts. Proficient readers use strategies, such as forming visual images while reading, connecting the information to practical situations or previous knowledge, recalling settings and events that are similar to that which is being read, predicting, and asking questions (Hurst, 2005; Guthrie \& Alvermann, 1999; Boakye, Pretorius, \& van Dyke, 2012. Readers who use a wide range of appropriate reading strategies, such as those mentioned above, have high reading proficiency levels and perform better academically (Nel, Dreyer, \& Klopper, 2004; Singhal, 2001).

Besides the cognitive strategies that are used for comprehension, metacognitive strategies are used to monitor comprehension; in other words to enable readers to know whether they are comprehending or not. Consequently, Singhal (2001) notes that if a reader is not aware of his or her own limitations he/she will not be able to use strategies that will assist comprehension. In a study conducted by Nel, et al. (2004), it was evident that inefficient readers had less elaborate metacognitive knowledge about reading strategies than did efficient readers. The ability to use appropriate strategies contributes to, and influences the belief in self-efficacy. A needs analysis is necessary to indicate whether students employ strategies and, if they do, which strategies and how they are used. This information will assist in designing effective interventions to improve students' use of strategies and, consequently, self-efficacy.

\subsubsection{Self-efficacy in Reading}

Self-efficacy in reading refers to the belief in one's ability to read successfully. Self-efficacy is the affective variant of strategy use and they both influence reading proficiency levels considerably (Boakye, 2015a). High self-efficacy promotes metacognitive awareness and contributes to reading proficiency. Students who are aware of their reading practices are likely to use appropriate strategies, and usually believe that they can read successfully. Studies have shown a relationship between a high level of self-efficacy and the use of appropriate reading strategies (Naseri \& Zaferanieh, 2012; Shang, 2010; Zare \& Mobarakeh, 2011). Ghonsooly and Elahi (2010) found a positive relationship between first-year university students' reading self-efficacy and their reading proficiency. More specifically, they found that high self-efficacious students performed better than low self-efficacious students in reading assessments.

\subsubsection{Reading Habits}

Students' reading habits are determined by what they read and how frequently they read. Kennedy and Trong (2010) point out that the frequency with which students read and the type of texts they read influence their reading proficiency. Furthermore, they argue that students' reading habits play an important role in successful reading and are influenced by both the home and the school environment. Reading for pleasure has been shown to influence reading proficiency by increasing vocabulary, word recognition, as well as an awareness of language structure and organisation (Day, 2010).

\subsubsection{Attitude towards Reading}

Reading attitude is referred to as 'a system of feelings related to reading, which causes a learner to approach or avoid a reading situation' (Guthrie \& Knowles, 2001 p. 161; McKenna, 2001, p. 136). Students' reading experience may influence their attitudes towards reading, and may determine their willingness to read (Grabe \& Stoller, 2011). In addition, Guthrie and Wigfield (2000) and McKenna (2001, p. 135) believe that a positive attitude is vital in promoting engaged readers. Roberts and Roberts (2008) point out that positive attitudes are essential in promoting deep reading, which is crucial for comprehension. Kirmizi (2011) found that attitude is a significant predictor of the use of reading strategies and consequently, of reading proficiency.

\subsubsection{Socioeconomic Status, the School System and Reading Proficiency}

As pointed out earlier, socioeconomic status influences learners' reading proficiency (Pretorius, 2010; Taylor \& $\mathrm{Yu}, 2009$ ). The socioeconomic status of a student may determine the school he/she would attend, and the school, in turn, influences factors such as the amount of exposure to texts, methods of reading instruction, and the frequency of reading (Currin \& Pretorius, 2010; Taylor \& Yu, 2009; Van Staden \& Bosker, 2011). Students from low socioeconomic status homes, who are generally indigenous South African language speakers may experience greater reading challenges of a specific nature than other students, given their backgrounds of limited 
exposure to texts owing to, among others, a lack of resources (Boakye, 2015b; Boakye \& Southey, 2008; Taylor $\&$ Yu 2009). It is therefore important to identify the backgrounds and reading profiles of these students in order to tailor interventions that meet their reading needs.

This paper reports on a study that explored students' reading profiles as a needs analysis for an intervention programme to improve the reading proficiency of first-year Sociology students. The aim was to determine the social, affective and cognitive factors that influence first-year Sociology students' academic reading proficiency.

While the questions on reading experience and socioeconomic status provided information on social factors, the attitude and self-efficacy sections elicited responses with regard to their affective reading levels. The questions focusing on strategy use, provided information on their use of reading strategies, which indirectly indicates their reading ability and their cognitive reading levels. The methodological aspects of the study are explained below.

\section{Methodology}

The aim of the study was to explore the reading backgrounds of first-year Sociology students in order to determine the factors that influence their reading proficiency. The study also sought to investigate the reading challenges that these students face in order to inform and guide the reading intervention programme. The following questions were posed for the study:

- What is the reading profile of first-year Sociology students at this institution?

- Is there a relationship or correlation between the cohort of students' self-efficacy and reading strategies?

- How can the cohort of students' reading profiles be used to structure an intervention to meet their needs?

\subsection{Participants}

The participants were 80 first-year Sociology students who volunteered to complete the questionnaire. The population was therefore selected at random. The students were registered for different study fields.

\subsection{Instrument}

A questionnaire, consisting of 65 questions divided into six sections, was used to elicit students' cognitive, affective and social profiles in relation to reading. The six sections covered past reading experience, attitudes towards reading, reading self-efficacy, use of strategy, reading habits, and socioeconomic status. The questionnaire was compiled using questions from Grabe and Stoller (2011), Guthrie, Wigfield and Metsala et al. (1999) and other questions relevant to the study.

The first section required students to provide their childhood experiences in respect of reading (e.g. 'Before I could read, members of my family used to read to me'). This section also probed the level of support students received at home and at school in their reading endeavours (e.g. 'My mother or my teacher used to encourage me to read books'). The second section required information regarding students' attitude towards reading (e.g. 'Reading helps me understand difficult concepts'). In the third section, students' self-efficacy in reading and their reading challenges were explored (e.g. 'I have difficulty in extracting the main points in what I read'). The fourth section aimed at determining students' reading strategies, particularly the strategies used in academic reading (e.g. 'Before I read a book, I look at its content page and skim through it looking at headings and illustrations'). The fifth section covered students' reading habits, both for pleasure and for academic purposes (e.g. 'I read at least one novel each month'). The sixth section probed students' socioeconomic status and the type of school they had attended. Students were also asked to state their home language. The qualitative section comprised an open-ended question that required students to state their reading challenges so as to gain more insight into their difficulties (Cresswell 2009). For a more detailed version of the qualitative section see Boakye and Mai (2016).

\subsection{Procedure}

Ethical clearance for the study was obtained from the Registrar of Student Affairs. In addition, students read and signed an informed consent form that was provided with the questionnaire. Students were asked to volunteer to participate in the pilot study, and those who were willing, signed the informed consent form and completed the questionnaire at the end of a tutorial session in the second semester. Their responses were analysed quantitatively to determine the students' reading backgrounds. Secondly, a regression analysis was done with regard to students' reported use of strategies and their self-efficacy levels to determine if self-efficacy would predict the use of reading strategies and vice versa. Finally, content analysis was used to analyse the open-ended section of the questionnaire, using emerging themes.

\section{Findings}

The descriptive results are given in percentages, while the results of the regression analysis are shown by the 
significant $p$ values. The qualitative data are provided under emerging themes with examples from students' reports.

A breakdown of the students' home languages, schools attended and socioeconomic status showed that the majority of the students attended private and suburban schools (68\%); spoke English, Afrikaans or an indigenous African language as home language (69\%); and were from a higher socioeconomic group (i.e. middle class or affluent). The distribution in terms of school attended and home language is given in Table 1 below.

Table 1. Distribution of school attended, home language and socioeconomic status

\begin{tabular}{llllll}
\hline School attended & Private & Suburban & Township & Rural & \\
\hline \multirow{2}{*}{ Language } & $49 \%$ & $36 \%$ & $8 \%$ & $6 \%$ & \\
& English & Afrikaans & $\begin{array}{l}\text { Indigenous } \\
\text { African }\end{array}$ & Other African & Other \\
& $34 \%$ & $30 \%$ & $22 \%$ & $11 \%$ & $6 \%$ \\
Socioeconomic status & Affluent & Middle class & Lower class & & \\
& $13.75 \%$ & $77.50 \%$ & $7.50 \%$ & & \\
\hline
\end{tabular}

This information is necessary as research has shown that the socioeconomic status of readers influences their reading proficiency (Currin \& Pretorius, 2010 Taylor \& Yu, 2009). Also, in South Africa, the school attended and, to some extent, language groups may determine socioeconomic status, and the three factors may, individually or together, influence reading proficiency (Van Staden \& Bosker, 2011; Zimmerman, 2011).

\subsection{Descriptive Statistics}

The descriptive statistics shows how students responded to the questionnaire in relation to reading experience, attitude towards reading, self-efficacy, use of strategies, and reading habits.

\subsubsection{Reading Experience}

Students' reading experience in relation to this study comprise their interaction with books and printed material during their childhood and school education, such as visits to the library, reading time at school, frequency of reading, and literacy environment at school and at home.

The average response to this section showed that students overall had a positive reading experience. Almost all the questions elicited a positive response: an average of $68 \%$ of students agreed, $12 \%$ were uncertain and $21 \%$ disagreed. The positive responses to the individual questions (i.e. agree/agree strongly) ranged between $55 \%$ and $84 \%$. It seems the students who volunteered to answer the questionnaire, were mainly from high socioeconomic status homes and had attended private or suburban schools, where reading is encouraged. These students therefore seemed to have had positive reading experiences. However, only $31 \%$ of students agreed with question 9: 'I used to read a novel per week when I was in high school'. A considerable number of students (21\%) disagreed with the statement. These students may have attended rural or township schools, and may come from low socioeconomic status homes. As explained earlier, a number of these schools lack the necessary resources for literacy development. In addition, families of low socioeconomic status usually lack the resources necessary to promote reading development.

\subsubsection{Reading Attitude}

Students responded positively to questions on reading attitude (e.g. question 11: 'I have always believed that reading is a good thing to do' $-91 \%$ agreed; question 18: 'Reading helps me understand difficult concepts' $90 \%$ agreed). The average positive response was $77.6 \%$ and positive responses to individual questions ranged between $78 \%$ and $91 \%$. Students seemed to have positive attitudes towards reading. However, questions 15,16 and 17 showed that in specific instances, students' attitudes were rather negative. A substantial number of students reported negative attitudes: question 15 showed that $49 \%$ do not like reading difficult texts; question 16 showed that $63 \%$ feel too much reading is required in the Sociology module; and question 17 revealed that $40 \%$ find academic articles difficult to read. Although students were generally positive in their attitudes towards reading and perceived reading as a worthwhile activity, they seemed not to like or enjoy reading difficult texts such as academic articles. However, they agreed that if the assignment project was interesting (question 19), or if an interesting issue was discussed in class (question 20), they would be willing to read difficult material $(90 \%$ 
agreed) or would read more about it ( $77 \%$ agreed). The specific instances that yield negative attitudes have to be addressed in an intervention programme in order to promote positive reading attitudes in students.

\subsubsection{Self-efficacy}

Students' self-efficacy levels, overall, seemed to be satisfactory, with an average of $59 \%$ positive responses. However, for certain questions, students reported low self-efficacy. For example, question 28: 'I have difficulty in extracting the main points in what I read', did not elicit an overwhelmingly positive response $-55 \%$ indicated that they had no difficulty, $27 \%$ were uncertain and $18 \%$ said they experienced challenges in extracting main ideas. Question 32: 'I always find it difficult to synthesise ideas from different authors in order to write an assignment' yielded $43 \%$ who disagreed and $27 \%$ who agreed. This shows that although students were positive regarding certain questions relating to their self-efficacy, their answers to other questions pointed towards specific challenges with academic reading and writing at this level. However, $70 \%$ agree that academic reading takes up much of their time because too much reading is required for their fields of study (questions 16 and 35ii). Inefficient readers may find reading burdensome and overwhelming.

As to whether they perceive themselves as skilled readers (question 34), 18\% disagreed, 37\% were uncertain and only $44 \%$ agreed. The fact that less than half the students agreed, and the rest of them either disagreed or were uncertain (55\%), indicates that the majority of students may have low self-efficacy in specific areas of reading. Question 31 asked whether students needed help in order to understand their readings; $52 \%$ said they did not, but a considerable percentage, viz. $28 \%$, said they did. This is a further indication that a number of students face reading challenges and do not believe in their ability to read their Sociology texts successfully.

\subsubsection{Reading Strategies}

With regard to reading strategies, some questions elicited positive responses (e.g. question 44: 'I try to relate what I read with my own ideas and previous knowledge' - with $76 \%$ agreeing; and question 46 : 'I always re-read sections when I do not understand what I am reading' - with 94\% agreeing). From this self-report it would seem that students use metacognitive strategies. However, the responses to a number of questions in this category showed that the majority of students were using inappropriate cognitive strategies. For example, question 38: 'The first thing I do when I come across an unknown word is to look up the meaning' had $74 \%$ agreeing, although it is not the best answer. The first thing a good reader does when he/she does not understand a word is to guess or derive the meaning from the context, not to look it up in the dictionary. This shows that students do not use contextual clues to make meaning while reading, which may compound their comprehension problems. Using contextual clues to make meaning assists with comprehension.

\subsubsection{Reading Habits}

Students generally do not read. With regard to question 54: 'I read at least one novel each month', only $10 \%$ agreed strongly, and a mere $35 \%$ agreed in total. A considerable percentage, namely $26 \%$, disagreed. The effect of pleasure reading, of novels in particular, on reading proficiency has been well documented and therefore the responses to this question raise concerns. Students' responses to question 54 can be linked to their responses to question 7 on past reading experience (see above). With regard to question 7 - whether they had read novels at school level - a considerable number of students (21\%) reported that they had not. The responses to questions 7 and 54 indicate that students did not read for pleasure while at school and are still not reading for pleasure. Voluntary academic reading beyond their required reading was dealt with in question 55: 'I often go to the university library to look for information related to my courses'. Forty eight per cent of students disagreed with the statement and only $31 \%$ agreed. This indicates that the majority of students who took part in the study do not read beyond their textbooks and notes. In addition, more than half the students $(51 \%)$ indicated that they only read their prescribed books or texts when they have an assignment or test (question 57). It seems students only read when they are required to do so. In general, students reported poor reading habits.

The responses show that although students generally had positive reading experiences, their attitudes towards reading, their self-efficacy, use of strategies and reading habits were not very encouraging. An intervention therefore needs to address these affective and cognitive dimensions of reading. In addition to the descriptive analysis given above, a regression analysis was performed on the students' self-efficacy and strategy use.

\subsection{Relationship between Reading Strategy Use and Self-efficacy}

Because strategy use is influenced by self-efficacy (Naseri \& Zaferanieh, 2012; Shang, 2010; Zare \& Mobarakeh, 2011), a regression analysis of the students' self-efficacy levels and strategy use was done. The results showed a positive correlation between the two variables at $(\mathrm{r}=.386, \mathrm{p}<0.000)$. The independent variable, strategy use, predicted self-efficacy levels at $(\mathrm{F}=13.668, \mathrm{P}<0.000)$. In other words, if a student had low self-efficacy it was 
highly likely that he/she would use inappropriate reading strategies and vice versa. Students who used inappropriate strategies were also likely to have low self-efficacy levels. The results corroborate those of other studies (Nel, Dreyer, \& Klopper, 2004; Singhal, 2001), which show a strong relationship between self-efficacy and the use of reading strategies. Given that there is a correlation between these two factors, and that they have a great influence on reading proficiency, the two should be developed simultaneously for effective reading intervention.

\subsection{Reading Challenges}

The responses to the open-ended question on students' reading challenges showed specific areas of difficulty. A detailed report on the qualitative data is provided in Boakye and Mai (2016). Although the analysis showed that most of the students (74\%) encounter reading challenges with their Sociology texts, the responses also revealed the specific areas where students were facing challenges. Students reported reading challenges with regard to comprehension, vocabulary, density, extent of reading materials, and the language used inthe texts, as well as affective issues such as motivation and interest. The predominant areas in which reading challenges occur, are shown in Figure 1 below.

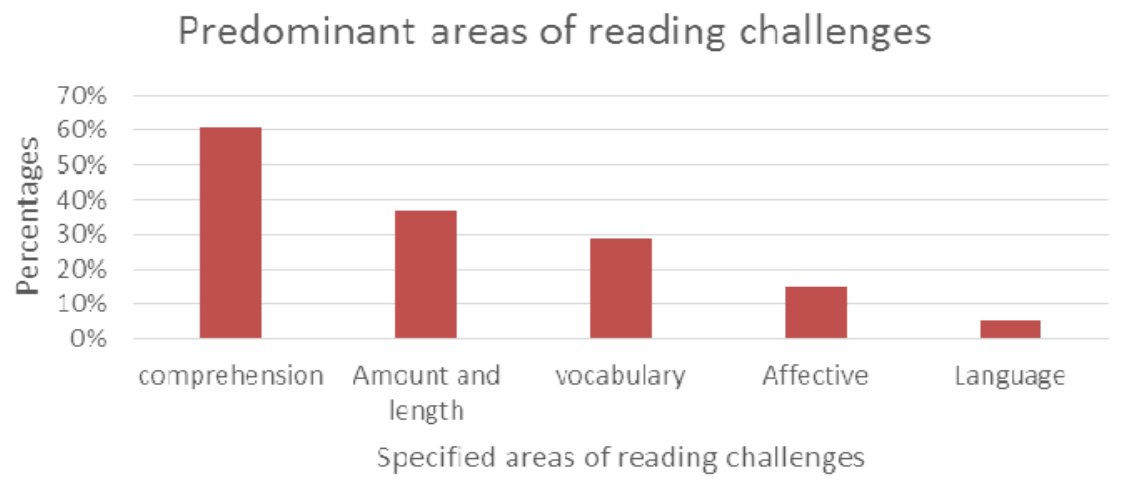

Figure 1. Predominant areas of reading challenges

In relation to comprehension, in which $61 \%$ of the students indicated that they had difficulties, statements included 'I struggle to identify main ideas in order to understand the texts'; 'Sometimes it is difficult to follow the main argument(s)'; 'It is difficult to interpret, process and understand'; and 'I find it difficult to distinguish between the relevant and less important information'. Students also expressed an inability to apply background knowledge, or having a lack thereof and added that background knowledge is required for most of the texts they read. Some students stated, almost in a state of despair: 'Confusing, overwhelming, challenging'; and 'I do not have an understanding of Sociology at all!'

With regard to reading material (i.e. difficulty experienced in reading journal articles; the abstract nature of Sociology texts; difficulty experienced in reading from a variety of sources), statements included: 'It is difficult to interpret information in journal articles'; 'The variety of readings from different authors intensifies the work due to different views and makes it difficult to grasp'; 'The content is complex and difficult to understand', and 'Difficult to understand the prescribed texts'.

In relation to vocabulary, students' responses included the following: 'Some articles are difficult to understand due to vocabulary'; 'Many sociological terms difficult to understand'; 'Readings are challenging and contain complex vocabulary'; and 'Difficult to understand the work because the texts use all these unfamiliar words' (Boakye \& Mai, 2016).

With regard to language, students made statements such as: 'Texts not in home language therefore lack of understanding'; 'I have difficulty understanding, due to texts not in my home language; lecturers don't give "in-depth" explanation'; 'Lectures are in English and makes it difficult to understand'; 'Texts are not in my mother-tongue so it is difficult to understand the new words due to the fact that I am not fond of reading' (Boakye \& Mai, 2016).

The amount of reading and the length of articles were mentioned as contributing factors to students' reading challenges. Statements pointing to these challenges included: 'Readings are too long and contribute to difficulty'; 
'It's hard to get to the main points due to the length of the readings'; 'I struggle to do the readings within the given time frames'; 'Readings are too long and too many'; and 'A lot of reading that is not thoroughly explained'. One student summed it up by stating: 'Sociology has too many readings!'.

Besides these cognitive challenges students also commented on the affective aspects of reading. For example, 'Readings are boring and meaning gets lost'; 'I am a slow reader and find the readings to be boring due to difficulty'; 'Difficulty arises when you do not find interest in the texts'; 'Long boring readings with difficult vocabulary'; 'Boring content results in struggling to read them'; and 'The challenge is trying to find interest in the readings, most of them are boring and too scientific'(Boakye \& Mai, 2016).

The qualitative data provided further insight into the challenges encountered by students. Students' comments show that they find reading material in Sociology challenging - especially with regard to vocabulary (e.g. concepts), diction, language, amount and extent of reading material, and general comprehension.

\section{Discussion}

The responses of the students indicate a poor reading profile. Although the majority reported having had a good reading experience, in general the quantitative analysis showed that students were using inappropriate strategies, had negative attitudes, low self-efficacy and poor reading habits. A number of the students could therefore be classified as struggling readers (Brenner, 2015) or frustration level readers (Pretorius, 2000). The results of both the qualitative and the quantitative analysis reveal specific areas of reading challenges, such as synthesising, distinguishing between main ideas and supporting details, identifying less important and important information in facilitating comprehension, as well as vocabulary, language and affective issues. These results have implications for the intervention programme, which has to be structured around these factors. A reading intervention for such students should seek to develop cognitive, as well as affective and social dimensions of reading. A number of recommendations are provided given the students' overall negative responses to the three dimensions of reading.

Firstly, in relation to the length and complexity of texts, scaffolding of reading strategies is recommended. Forty one per cent of students stated that they do not like reading difficult texts. Consequently, difficult texts should be introduced in a scaffolded manner to promote understanding and develop a positive attitude to reading. However, students stated that they would be willing to read difficult material if the topic was interesting. The programme should include texts that have been written in a more interesting manner, such as magazine and newspaper articles, or blog sites, so that students find them easier to comprehend. This will serve as a scaffold for prescribed journal articles or textbooks and will facilitate comprehension and promote positive attitudes.

The general response showed that most students were not using appropriate reading strategies. Explicit strategy instruction (cognitive and metacognitive) would provide students with effective reading strategies, increase their confidence and raise their self-efficacy levels. Strategies such as using contextual clues for unknown words, distinguishing between main ideas and supporting details, and applying background knowledge to texts, should form part of the intervention programme. Explicit strategy instruction in areas such as accessing prior knowledge, making and revising predictions, making inferences, asking questions, creating mental images, monitoring and repairing comprehension, providing mental or written summaries, are to be taught and practised using Sociology or relevant texts (Brenner, 2015, p. 6; Parrott \& Cherry, 2011). Parrott and Cherry's (2011) role-play techniques, which utilises characters such as 'discussion leader', 'creative connector', 'passionate reporter' would help to reinforce reading strategies. The regression analysis showed that students' strategy use predicted their self-efficacy and showed a significant correlation between the two factors. Consequently, these two aspects of reading should be developed simultaneously in order to achieve higher rate of success in improving reading proficiency.

Students' self-efficacy levels were low. Self-efficacy has a great influence on how students approach texts, and is linked to their reading proficiency (Grabe \& Stoller, 2011 Pajares, 2006). Students' low self-efficacy, revealed by the quantitative data, is corroborated in the qualitative data. Students seem to believe that their success in reading Sociology texts mainly depended on their lecturers. This shows that they do not believe in reading effectively on their own. Self-efficacy, the affective variant of metacognition, is important for promoting reading, as it determines whether a student will be willing to read, and also do so independently and frequently (Grabe \& Stoller (2011).

It is important that the reading intervention for this cohort of students include strategies to improve self-efficacy. The intervention should include explicit teaching of strategies: the techniques provided by Guthrie and Wigfield (2000) to ensure engaged reading, such as using interesting and relevant texts; and strategies advocated by Dörnyei (2001), such as providing positive and frequent feedback. Dörnyei (2001) explains that in order to 
increase motivation for reading and, concomitantly, self-efficacy levels, positive and frequent strategy instruction and feedback should be provided, among others. In addition, self-efficacy levels can be increased by using texts that are at students' level of comprehension, or just above their comprehension level. If texts are extremely above readers' comprehension level, they lose motivation (Grabe \& Stoller, 2011) and read at frustration level (Pretorius, 2000), which contribute to boredom and a lack of interest and focus in reading, as reported by a number of students.

The majority of students reported poor reading habits, while others stated that the challenges they face in comprehending the texts are due to their slow reading and the fact that they do not read much. Extensive reading should be integrated in the reading programme to enable students to experience pleasure in reading and develop positive reading habits. The benefits of reading for pleasure to improve reading proficiency are well documented (Day, 2010; Kennedy \& Trong, 2010). Extensive reading improves comprehension, increases vocabulary, develops deep or engaged reading, and complements instruction on the use of strategies. It is hoped that the reading of novels, such as those by Bessie Head and Tsitsi Dangeremba will promote cultural awareness, provide joy and pleasure, and - most importantly - improve reading proficiency.

Although the majority of the students were from affluent and middle class homes, a small number $(7.50 \%)$ were from low socioeconomic status homes. Students from low socioeconomic status families whose parents are not likely to emphasise reading, would demonstrate a less positive attitude towards reading. Extensive reading serves to provide positive attitudes and increase students' willingness to read. Reading instruction should meet the needs of these students even if they are in the minority. According to Boughey (2009, online): '[i]f we don't do this, the young people who will learn to read and write in powerful ways are those who pick up those ways of reading and writing outside the formal learning environment - young people who are already privileged because of the educational and social background of their parents and what that exposes them to'.

Vocabulary and diction in Sociology texts were listed by students as posing challenges to their reading. Nation (2006) suggests that knowledge of $95 \%$ or more words facilitates understanding and that anything less hinders comprehension. The fact that $29 \%$ of the students listed vocabulary issues as challenging, indicates that this aspect of reading needs to be addressed. The difficulty in understanding words and concepts in a text, makes reading laborious and may lead to boredom. Activities to improve word recognition and increase students' knowledge of academic words and concepts will assist in this regard. Quizzes could be a great starting point to increase students' understanding of concepts. However, Roberts and Roberts (2008) caution that quizzes in Sociology do not enable students to read deeply and should be used sparingly. The use of concept cards could also be introduced and can be practised as a form of puzzle activity during tutorials (Weideman, 2006). By increasing students' word recognition in reading in some of these ways, affective issues such as boredom, lack of interest and focus would be minimised.

Furthermore, the qualitative data reveal that students find synthesising, to be very challenging. This skill could be taught through scaffolding. According to Hiebert et al. (2009), scaffolding makes texts more accessible. Less difficult texts such as newspapers or blogs could be used for synthesising to enable the students to acquire this skill before journal articles and complex texts are introduced.

The qualitative data revealed comprehension to be the dominant challenge. By providing students with explicit instruction on strategies, such as summarising and applying background knowledge, they would be able to read strategically, which will improve comprehension. Deep reading activities, where students search for meaning while engaging with texts in depth, would also help to improve comprehension. (Parrott \& Cherry, 2011; Roberts \& Roberts, 2008). Parrott and Cherry (2011) suggest activities that would enable students to read their Sociology texts and also to participate in class discussions. As indicated earlier, scaffolding of texts, in other words getting students to approach difficult texts gradually by first reading summarised versions, would also help improve comprehension (Boakye \& Mbirimi 2015; Roberts \& Roberts 2008).

With regard to language as a contributing factor to students' reading challenges, translanguaging as a teaching approach could be used to improve comprehension (Garcia, 2009a Lewis, Jones, \& Baker, 2012). Although English is the language of instruction, it is an additional language for the majority of students. Students' home languages and literacy practices could be used as a resource for comprehension before they engage deeply with English texts. It is hoped that this will lead to better and easier understanding of concepts and theories, provide social relevance, and promote cultural consciousness among students (Boakye, 2015b).

To summarise, the students' reading profiles show low affective and cognitive reading levels. For example, the profiles show that a number of students had had poor reading experience $(69 \%)$, and also reported poor reading habits $(65 \%)$, low self-efficacy (54\%), inappropriate use of strategies $(74 \%)$, and specific challenges such as 
comprehension (61\%) vocabulary $(29 \%)$, diction, language $(5 \%)$, number and length of the texts $(38 \%)$, as well as affective issues such as boredom and a lack of interest and motivation (15\%). These issues are to be addressed in the intervention programme using the techniques discussed above to improve this cohort of students' reading of Sociology texts.

\section{Conclusion}

This paper has shed light on students' reading profiles and backgrounds. It has shown that students' self-efficacy, reading habits, strategy use, reading experience, and attitudes towards reading are far from adequate. In addition, the needs analysis showed specific areas of reading challenges such as comprehension, vocabulary, language, number and length of texts, as well as affective issues such as boredom, disinterest and a lack of focus. This information will make it possible for educators to focus on these problematic aspects in a reading intervention programme, in order to address specific needs and provide a more effective intervention. A number of reading strategies, such as scaffolding, summarising, explicit strategy instruction, role-play, extensive reading, and translanguaging, which can be used to address these challenges, are to be included in the intervention programme.

The paper argues that a needs analysis, which focuses on the social, affective and cognitive reading backgrounds of students, is mandatory to achieve optimal results in a reading intervention, and that any intervention must be aimed at developing the reading proficiency of the entire cohort of students.

Since the study did not include a standardised test, future research could include a standardised reading proficiency test to determine students' actual level of reading proficiency as part of the needs analysis in order to arrive at a more complete analysis, and to reinforce the arguments in this paper.

\section{Acknowledgement}

This research was made possible by the National Research Foundation's grant for Competitive Support for Unrated researchers (CSUR).

\section{References}

Afflerbach, P., Pearson, P. D., \& Scott, S. G. (2008). Clarifying differences between reading skills and reading strategies. The Reading Teacher, 61(5), 364-373. https://doi.org/10.1598/RT.61.5.1

Alderson, J. C. (2000). Assessing reading. Cambridge: Cambridge University Press. https://doi.org/10.1017/CBO9780511732935

Bandura, A. (1986). Social foundations of thought and action: A social cognitive theory. Englewood Cliffs, NJ: Prentice-Hall.

Boakye, N. A. Y. (2012). A socio-affective approach to improving students' reading comprehensiabilities (Unpublished doctoral thesis.) University of Pretoria, Pretoria, South Africa.

Boakye, N. A. Y. (2015a). The relationship between self-efficacy and reading proficiency of first-year students: An exploratory study. Reading \& Writing, 6(1) Art \# 52. https://doi.org/10.4102/rw.v6i1.52

Boakye, N. A. Y. (2015b). The social dimension of reading literacy development in South Africa: Bridging inequalities among the various language groups. International Journal of the Sociology of Language, 234, 133-156. https://doi.org/10.1515/ijsl-2015-0008

Boakye, N., \& Mbirimi, V. (2015). Multilingual pedagogy in higher education: Lecturers' perceptions of translanguaging in promoting academic literacy. In L. Makalela (Ed.), New directions in language and literacy education for multilingual classrooms (pp. 153-174). Cape Town: CASAS.

Boakye, N. A. Y., \& Mbong, M. (2016). A needs analysis for a discipline-specific reading intervention. English Language Teaching, 9(3), 235-247. https://doi.org/10.5539/elt.v9n3p235

Boakye, N., \& Southey, L. (2008). Investigating students' motivation and attitudes towards reading. Journal for Language Teaching, 42(2), 7-24.

Boughey, C. (2009). South Africa: University students can't read? University World News online 0090. Retrieved from www.universityworldnews.com/article.php?story $=20090827173247724$

Brenner, D. (2015). Supporting struggling readers in social studies education with Apex Learning Digital Curriculum.

Chen, Y. (2006). From common core to specific. Asian ESP Journal, 1(3), 24-47.

Creswell, J. W. (2009). Research design: Qualitative, quantitative and mixed methods approaches. Thousand 
Oaks, CA: SAGE.

Currin, S., \& Pretorius, E. J. (2010). The culture of the sharp pencil: Can a literacy intervention lever school change? Reading \& Writing, 1(1), 23-46. https://doi.org/10.4102/rw.v1i1.3

Day, R. R. (2010). The benefits of extensive reading (ER).

Dörnyei, Z. (2001). Motivational strategies in the language classroom. Cambridge: Cambridge University Press. https://doi.org/10.1017/CBO9780511667343

Boakye, N., Pretorius, R., \& Van Dyk, T. (2012). Academic reading: EOT 161. Pretoria: University of Pretoria.

Garcia, O. (2009a). Bilingual education in the $21^{\text {st }}$ century: A global perspective. Oxford: Wiley-Blackwell.

García, G. L. (2010). The importance of needs analysis in syllabus and course design. The CMC project: A case in point. In L. Pérez Ruiz, I. Parrado Román, \& P. Tabarés Pérez (Eds), Estudios de Metodología de la Lengua Inglesa (V) (pp. 101-111). Valladolid: Centro Buendía, Universidad de Valladolid. Retrieved from http://www.spertus.es/Publications/Lidia/valladolid.pdf

Ghonsooly, B., \& Elahi, M. (2010). Learners' self-efficacy in reading and its relation to foreign language anxiety and reading achievement. Journal of English Language Teaching and Learning, 53(2), 45-67.

Grabe, W., J. T., \& Stoller, F. L. (2011). Teaching and researching reading. London: Routledge.

Guthrie, J. T. (2008). Reading motivation and engagement in middle and high school: Appraisal and intervention. In J.T. Guthrie (Ed.), Engaging adolescents in reading (pp. 1-16). London: Corwin Press.

Guthrie, J. T., \& Alvermann, D. (1999). Engagement in reading: Processes, practices, and policy implications. New York: Teachers College Press.

Guthrie, J. T., \& Knowles, K. T. (2001). Promoting reading motivation. In L. Verhoeven, \& C. E. Snow (Eds), Literacy and motivation: Reading engagement in individuals and groups (pp. 159-176). Mahwah, NJ: Lawrence Erlbaum.

Guthrie, J. T., \& Wigfield, A. (2000). Engagement and motivation in reading. In P. B. Karmil, \& P. D. Mosenthal (Eds.), The handbook of reading research (Vol III, pp. 403-420). Mahwah, NJ: Lawrence Erlbaum.

Guthrie, J. T., Wigfield, A., Matsala, J. L., \& Cox, K. E. (1999). Motivational and cognitive predictors of text comprehension and reading amount. Scientific Studies of Reading, 3(3), 231-256. https://doi.org/10.1207/s1532799xssr0303_3

Hiebert, E. H., Menon, S., Martin, L. A., \& Bach, K. E. (2009). Online scaffolds that support adolescents' comprehension. Seattle, WA: Apex Learning.

Howard, E. L. (2004). Classic readings in Sociology. Belmont, CA: Wadsworth.

Hurst, B. (2005). My journey with learning logs. Journal of Adolescent and Adult Literacy, 49(1), 42-46. https://doi.org/10.1598/JAAL.49.1.5

Hutchinson, T., \& Waters, A. (1987). English for specific purposes: A learning-centered approach. Cambridge Cmbridge University Press. https://doi.org/10.1017/cbo9780511733031

Kennedy, M. A., \& Trong, K. L. (2010). Influence of home environment on reading motivation and reading comprehension.

Kirmizi, F.S. (2011). The relationship between reading comprehension strategies and reading attitude. Education, 39 (3), 289-303.

Lewis, G., Jones, B., \& Baker, C. (2012). Translanguaging: Developing its conceptualization and contextualization. Educational Research and Evaluation, 18, 655-670. https://doi.org/10.1080/13803611.2012.718490

McKenna, M. C. (2001). Development of reading attitudes. In L. Verhoeven, \& C. E. Snow (Eds), Literacy and Motivation.pp. 135-176). Mahwah, NJ: Lawrence Erlbaum.

Naseri, M., \& Zaferanieh, E. (2012). The relationship between reading self-efficacy beliefs, reading strategy use and reading comprehension level of Iranian EFL learners. World Journal of Education, 2(2), 64-75. https://doi.org/10.5430/wje.v2n2p64

Nation, I. S. P. (2006). How large a vocabulary is needed for reading and speaking? Canadian Modern Language Review, 63, 59-82. https://doi.org/10.3138/cmlr.63.1.59 
Nel, C., Dreyer, C., \& Klopper, M. (2004). An analysis of the reading profiles of first-year students at Potchefstroom University: A cross-sectional study and a case study. South African Journal of Education, 24(1), 95-103.

Pajares, F. (2006). Self-efficacy during childhood and adolescence: Implications for teachers and partners. In F. Pajares, \& T. Urden (Eds), Self-efficacious beliefs of adolescents (pp. 339-467). Greenwich, CT: Information Age.

Parrott, H. M., \& Cherry, E. (2011). Using structured reading groups to facilitate deep reading. American Sociological Association, 39(4), 354-370.

Pelisson, G. (2003). Mastering social studies skills. New York: AMSCO School Publications.

Pretorius, E. J. (2000). Inference generation in the reading of expository texts by university students. (Unpublished doctoral thesis.) University of South Africa, Pretoria, South Africa.

Pretorius, E. J. (2002). Reading ability and academic performance in South Africa: Are we fiddling while Rome is burning? Language Matters, 33, 91-103. https://doi.org/10.1080/10228190208566183

Pretorius, E. J. (2010). Complexity in reading: Leaving aside Occam's razor for now. Southern African Linguistics and Language Studies, 28(4), 339-356. https://doi.org/10.2989/16073614.2010.548016

Richards, J. C. (2002). Curriculum development in language teaching. Cambridge, Mass.: CUP.

Roberts J. C. \& Roberts, K. A. (2008). Deep reading, cost/benefit, and the construction of meaning: Enhancing reading comprehension and deep learning in Sociology courses. Teaching Sociology, 36(2), 125-140. https://doi.org/10.1177/0092055X0803600203

Shang, H. F. (2010). Reading strategy use, self-efficacy and EFL reading comprehension. The Asian EFL Journal, $12(2), 18-42$.

Singhal, M. (2001). Reading proficiency, reading strategies, metacognitive awareness and L2 readers. The Reading Matrix, 1(1), 1-23.

Sousa, D. A. (2006). How the brain works. Thousand Oaks, CA: Corwin.

Taylor, S., \& Yu, D. (2009). Socio-economic status and educational achievement: Does education provide a stepping stone out of poverty in South Africa? Transformation Audit, 66-75.

Titcomb, A. L. (2000). Need analysis. ICYF evaluation concept sheet. University of Arizona. Retrieved from https://extension.arizona.edu/evaluation/sites/extension.arizona.edu.evaluation/files/docs/needs.pdf

Trabasso, T., \& Bouchard, E. (2002). Teaching readers how to comprehend text strategically. In C. C. Block, \& M. Pressley, (Eds), Comprehension instruction: Research-based best practices (pp. 176-200). New York: Guilford Press.

Van Staden, S., \& Bosker, R. (2011). Factors that affect South African reading literacy achievement: Evidence from prePIRLS 2011. South African Journal of Education, 34(3), 1-9. https://doi.org/10.15700/201409161059

Veena, P. (2016). Importance of needs analysis in curriculum development for vocational purposes. International Journal of English Language, Literature and Humanities, 4(5), 440-449.

Vygotsky, L. (1978). Interaction between learning and development. In M. Gauvainim, \& M. Cole (Eds), Readings on the development of children. New York: Freeman. Retrieved from http://www.psy.cmu.edu/ siegler/vygotsky78.pdf3

Weideman, A. (2006). Academic Literacy: Prepare to learn. Pretoria: Van Schaik.

Yamane, D. (2006). Course preparation assignments: A strategy for creating discussion-based courses. Teaching Sociology, 34(3), 236-248. https://doi.org/10.1177/0092055X0603400303

Zare, M., \& Mobarakeh, S. D. (2011). The relationship between self-efficacy and use of reading strategies: The case of Iranian senior high school students. Studies in Literature and Language, 3(3), 98-105.

Zimmerman, L. (2011). The influence of schooling conditions and teaching practices on curriculum implementation for Grade 4 reading literacy development. (Unpublished doctoral thesis.) University of Pretoria, Pretoria, South Africa. 


\section{Appendix}

\section{QUESTIONNAIRE: EXPLORING STUDENTS' READING PROFILES FOR A READING INTERVENTION PROGRAMME}

Dear Student

Thank you for your willingness to participate in this survey. Your input is greatly appreciated as it will assist in designing a suitable academic reading intervention for Sociology students. Kindly note that all your answers are important and no answer will be considered incorrect. We value your honest and sincere opinions. Please note that all your answers will remain anonymous. Even though your student numbers will be required on the questionnaire, they will only be used for tallying purposes. There are no disadvantages in responding to this questionnaire.

For office use

Respondent number 
Please tick (using an X) the number that best reflects your opinion. accurately

\begin{tabular}{|c|c|c|c|c|c|}
\hline Past experiences with reading & 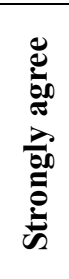 & 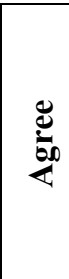 & & 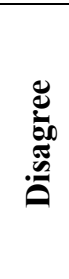 & 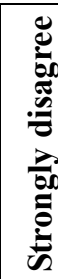 \\
\hline 1 I read books for pleasure during my childhood. & 1 & 2 & 3 & 4 & 5 \\
\hline 2. I started reading between the ages of 4-6. & 1 & 2 & 3 & 4 & 5 \\
\hline $\begin{array}{l}\text { 3. Before I could read for myself members of my family used to read } \\
\text { to me. }\end{array}$ & 1 & 2 & 3 & 4 & 5 \\
\hline 4. I started reading in my mother tongue as a child. & 1 & 2 & 3 & 4 & 5 \\
\hline 5. My mother used to encourage me to read a lot of books. & 1 & 2 & 3 & 4 & 5 \\
\hline $\begin{array}{l}\text { 6. When I was a child I often visited the library to read or to borrow } \\
\text { books to read at home. }\end{array}$ & 1 & 2 & 3 & 4 & 5 \\
\hline 7. I used to read a novel per week when I was in high school. & 1 & 2 & 3 & 4 & 5 \\
\hline 8. My primary school teachers used to encourage me to read novels. & 1 & 2 & 3 & 4 & 5 \\
\hline 9. There have always been books in my family's home. & 1 & 2 & 3 & 4 & 5 \\
\hline 10. My high school teachers emphasised reading for pleasure. & 1 & 2 & 3 & 4 & 5 \\
\hline \multicolumn{6}{|l|}{ Attitude towards reading } \\
\hline 11. I have always believed that reading was a good thing to do. & 1 & 2 & 3 & 4 & 5 \\
\hline 12. I have favourite subjects that I read about. & 1 & 2 & 3 & 4 & 5 \\
\hline 13. I enjoy reading when I know the subject matter. & 1 & 2 & 3 & 4 & 5 \\
\hline 14. Reading well will help me with my studies. & 1 & 2 & 3 & 4 & 5 \\
\hline 15. I do not enjoy reading difficult texts. & 1 & 2 & 3 & 4 & 5 \\
\hline 16. I feel there is too much to read in the Sociology course. & 1 & 2 & 3 & 4 & 5 \\
\hline 17. I find academic articles difficult to read. & 1 & 2 & 3 & 4 & 5 \\
\hline 18. Reading helps me understand difficult concepts. & 1 & 2 & 3 & 4 & 5 \\
\hline $\begin{array}{l}\text { 19. If the assignment project is interesting, I can read difficult } \\
\text { material. }\end{array}$ & 1 & 2 & 3 & 4 & 5 \\
\hline $\begin{array}{l}\text { 20. If my tutor/lecturer discusses something interesting, I will read } \\
\text { more about it. }\end{array}$ & 1 & 2 & 3 & 4 & 5 \\
\hline
\end{tabular}

\begin{tabular}{|c|c|c|c|c|c|}
\hline \multicolumn{6}{|l|}{ Reading and self-efficacy } \\
\hline 21. I think I read well and with understanding. & 1 & 2 & 3 & 4 & 5 \\
\hline 22. I read slowly so I have problems with understanding. & 1 & 2 & 3 & 4 & 5 \\
\hline $\begin{array}{l}\text { 23. I have difficulty in completing the reading assignments given to } \\
\text { me. }\end{array}$ & 1 & 2 & 3 & 4 & 5 \\
\hline 24. I read slowly so it makes me tired and bored. & 1 & 2 & 3 & 4 & 5 \\
\hline $\begin{array}{l}\text { 25. I have difficulty in understanding words (50\% or more) in my } \\
\text { reading assignments. }\end{array}$ & 1 & 2 & 3 & 4 & 5 \\
\hline $\begin{array}{l}\text { 26. I have to translate what I read into my home language before I } \\
\text { really understand. }\end{array}$ & 1 & 2 & 3 & 4 & 5 \\
\hline
\end{tabular}




\begin{tabular}{|l|l|l|l|l|l|}
\hline $\begin{array}{l}\text { 27. I have difficulty in understanding the texts I have to read at } \\
\text { university, especially the vocabulary. }\end{array}$ & 2 & 3 & 4 & 5 \\
\hline 28. I have difficulty in extracting the main points in what I read. & 1 & 2 & 3 & 4 & 5 \\
\hline $\begin{array}{l}\text { 29. When I read I am always able to share and explain what I } \\
\text { understood with friends and classmates. }\end{array}$ & 1 & 2 & 3 & 4 & 5 \\
\hline $\begin{array}{l}\text { 30. I always find it difficult to answer questions based on readings } \\
\text { assigned by lecturers and tutors. }\end{array}$ & 1 & 2 & 3 & 4 & 5 \\
\hline $\begin{array}{l}\text { 31. I always need help from friends, lecturers or tutors for me to } \\
\text { understand the main ideas after reading academic texts. }\end{array}$ & 1 & 2 & 3 & 4 & 5 \\
\hline $\begin{array}{l}\text { 32. I always find it difficult to synthesise ideas from different authors } \\
\text { in order to write an assignment. }\end{array}$ & 1 & 2 & 3 & 4 & 5 \\
\hline 33. I always try to understand the questions before answering. & 1 & 2 & 3 & 4 & 5 \\
\hline $\begin{array}{l}\text { 34. I am a fast, highly skilled reader and I do not have problems } \\
\text { understanding what I read. }\end{array}$ & 1 & 2 & 3 & 4 & 5 \\
\hline 35. Academic reading takes up most of my time because: & 1 & 2 & 3 & 4 & 5 \\
\hline i. I am a slow reader. & 1 & 2 & 3 & 4 & 5 \\
\hline ii. there is too much reading required in my field of study. & 1 & 2 & 3 & 4 & 5 \\
\hline
\end{tabular}

\section{Reading strategies}

36. When I read a novel, I read it in a different way from when I read a textbook.

37. Before I read a textbook, I look at its contents page and through it looking at headings and illustrations.

38. The first thing I do when I come across an unknown word is to look up the meaning.

39. I record new words and try to memorise them with their meanings.

40. I ignore diagrams, maps, graphs, charts, which I come across in the course of my reading.

41. I always take notes when I am reading.

42. I always underline or highlights parts that I think are important when I am reading.

43. I always draw my own mind maps or flowcharts of the information about which I'm reading.

44. I try to relate what I read to my own ideas and previous knowledge.

45. I use questions like why, what and how to help me understand my reading better.

46. I always re-read sections when I do not understand what I am reading.

47. I form visual images when I read.

48. I summarise the main ideas in my head as I read.

49. The tutorials helped me understand difficult concepts.

50. The tutorials helped me understand the assigned readings better.

51. The mind maps helped me to identify the main points and

\begin{tabular}{|c|c|c|c|c|}
\hline 1 & 2 & 3 & 4 & 5 \\
\hline 1 & 2 & 3 & 4 & 5 \\
\hline 1 & 2 & 3 & 4 & 5 \\
\hline 1 & 2 & 3 & 4 & 5 \\
\hline 1 & 2 & 3 & 4 & 5 \\
\hline 1 & 2 & 3 & 4 & 5 \\
\hline 1 & 2 & 3 & 4 & 5 \\
\hline 1 & 2 & 3 & 4 & 5 \\
\hline 1 & 2 & 3 & 4 & 5 \\
\hline 1 & 2 & 3 & 4 & 5 \\
\hline 1 & 2 & 3 & 4 & 5 \\
\hline 1 & 2 & 3 & 4 & 5 \\
\hline 1 & 2 & 3 & 4 & 5 \\
\hline 1 & 2 & 3 & 4 & 5 \\
\hline 1 & 2 & 3 & 4 & 5 \\
\hline 1 & 2 & 3 & 4 & 5 \\
\hline
\end{tabular}




\begin{tabular}{|l|l|l|l|l|l|}
\hline supporting details. & \multicolumn{2}{|l|}{} & \multicolumn{2}{l|}{} \\
\hline Reading habits & \multicolumn{2}{|l|}{} & \multicolumn{2}{|l|}{} \\
\hline 52. I read for pleasure. & 1 & 2 & 3 & 4 & 5 \\
\hline 53. I read magazines and or newspapers every week. & 1 & 2 & 3 & 4 & 5 \\
\hline 54. I read at least one novel each month. & 1 & 2 & 3 & 4 & 5 \\
\hline $\begin{array}{l}\text { 55. I often go to the university library to look for information } \\
\text { related to my courses. }\end{array}$ & 1 & 2 & 3 & 4 & 5 \\
\hline 56. I always read my lecture notes and prescribed materials. & 1 & 2 & 3 & 4 & 5 \\
\hline $\begin{array}{l}\text { 57. I only read academic articles and prescribed texts when I have } \\
\text { an assignment. }\end{array}$ & 1 & 2 & 3 & 4 & 5 \\
\hline 58. I have designed a study timetable for my personal study. & 1 & 2 & 3 & 4 & 5 \\
\hline 59. I strictly follow my study timetable. & 1 & 2 & 3 & 4 & 5 \\
\hline
\end{tabular}

\section{Reading and socioeconomic status}

60. I went to:

Please tick

\begin{tabular}{|l|l|l|l|}
\hline A township school & Rural school & Private school & Urban school \\
\hline
\end{tabular}

61. How would you rate your family?

Please choose

\begin{tabular}{|l|l|l}
\hline Lower class & Middle class & Affluent \\
\hline
\end{tabular}

62. Briefly explain the differences between the reading challenges you had at high school (if you had any) and the reading challenges you are currently experiencing in your subject field (e.g. Sociology)

\begin{tabular}{|l|l|l|l|l|l|}
\hline Personal information & & & & & \\
\hline 63.Gender & $\mathrm{F}$ & & $\mathrm{M}$ & & \\
\hline 64.Mother tongue/home language & English & Afrikaans & SA African & Other African & Other \\
\hline 65.Student number & & & & & \\
\hline
\end{tabular}

\section{Thank you for filling in the questionnaire.}

\section{Copyrights}

Copyright for this article is retained by the author(s), with first publication rights granted to the journal.

This is an open-access article distributed under the terms and conditions of the Creative Commons Attribution license (http://creativecommons.org/licenses/by/4.0/). 